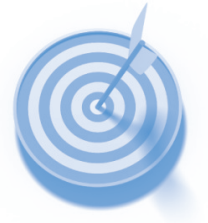

\section{Lynn Moran \\ Department of Physics \\ University of Liverpool \\ Liverpool \\ L69 3BX}

\section{lynn.moran@liverpool.ac.uk}

The Undergraduate Physics Olympics is a team based event run during the University's

Welcome Week encouraging new physics students to get to know one another while doing some fun, competitive physics experiments.

\title{
Mission to Mars: a one-week introductory project for new physics students
}

\begin{abstract}
A new event to help smooth the induction of year 1 students to university was run in the Physics Department on a trial basis in the academic year 2009/10 and extended in 2010/11. The event took place in the first week of term with the aim of introducing the students to the Department and the level of engagement expected of them. After some ice-breakers and simple problem-solving, an open-ended physics problem on a topical issue was presented to the students who were organised to work in groups.
\end{abstract}

In addition to working on the project problem, the students completed some on-line assignments (in order to introduce them to Pearson's Mastering Physics software which the Department has adopted after a successful pilot). In the first year the event ran for 2.5 days, with the groups producing a 1-page report (requiring them to encounter the printing system) and a poster for a poster session. In 2010/11 teams (each containing 5 groups) presented their results to an audience of academics (and fellow students), emphasising the importance of communication skills. The evaluation results indicate that it was a beneficial experience, and the effect of the changes in the second year has been investigated.

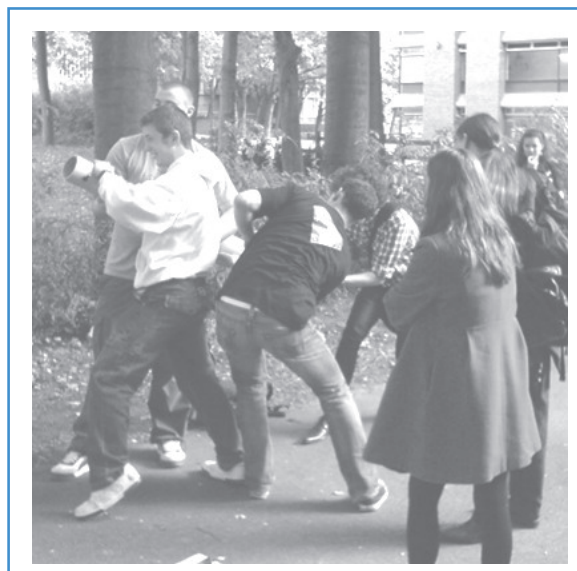

Figure 1: Students taking part in the Undergraduate Physics Olympics

\section{Background}

Project-Based Learning was successfully introduced for year 1 students in one module in the academic year 2008/09. The advantages to the students were that they engaged better with the material and in their own words 'had to read the book to be able to answer the questions.' It was decided that it would benefit the students to be required to try (ideally master) independent learning techniques earlier in their university career.

The Undergraduate Physics Olympics is a team based event run during the University's Welcome Week encouraging new physics students to get to know one another while doing some fun, competitive physics experiments (figures 1 and 2$)^{1}$.

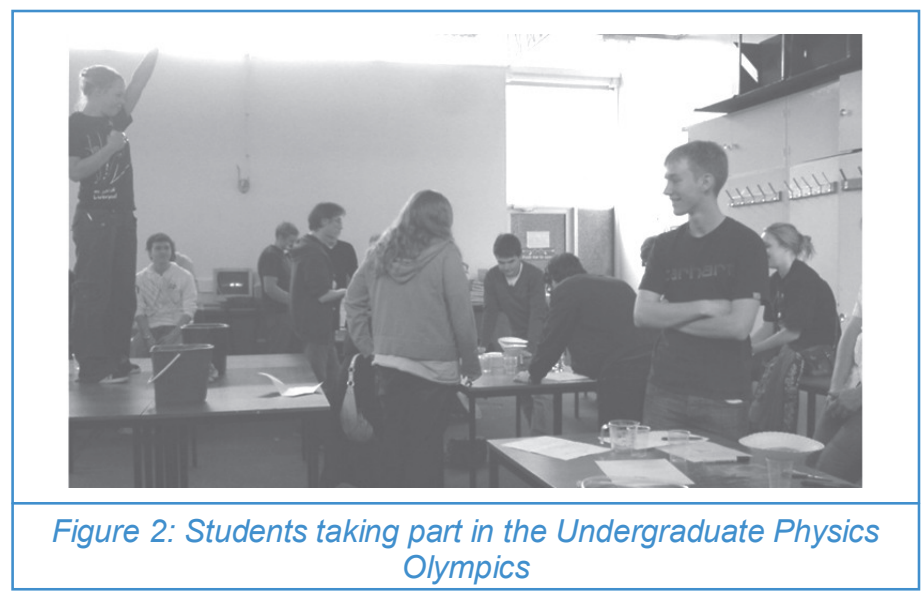


A more academic introductory project to follow this during the first week of term, immediately after Welcome Week was developed with the following aims:

- To encourage students to realise the level of work expected

- To give students experience of working in a team

- To help students settle into University life quickly

- To enable students to acclimatise to their new environment/learn their way around the Department

- To allow students to meet academic staff in an academic environment

- To help students to get to know fellow physics students

- To require students

to organise their computer account

to register for Mastering Physics

to learn how to obtain printer credit

to learn to use a timetable

\section{Method}

2009

During the first 2.5 days of term, students were put in teams of 8 and set a project to complete. After introductory sessions to help develop team-working skills and give them a clear idea of what was expected of them, the students were allowed time to work on the project with a member of staff available to offer support and clarify any scientific points. A poster and final report (limited to one page) were due on the Wednesday at $12 \mathrm{pm}$. At the poster session, staff questioned students, and marked their project and responses. Prizes were given for the best poster at a concluding session, which took place immediately afterward. The Project Text was adapted from a Climate Change PBL problem developed at Leicester².

Not all politicians agree that $\mathrm{CO}_{2}$ emissions are responsible for global warming so it is not surprising that they have seized on a recent idea that the observed increase in atmospheric temperature since the start of industrialization tracks the heat dumped into the atmosphere by power stations. How would you brief the minister responsible for carbon reduction?

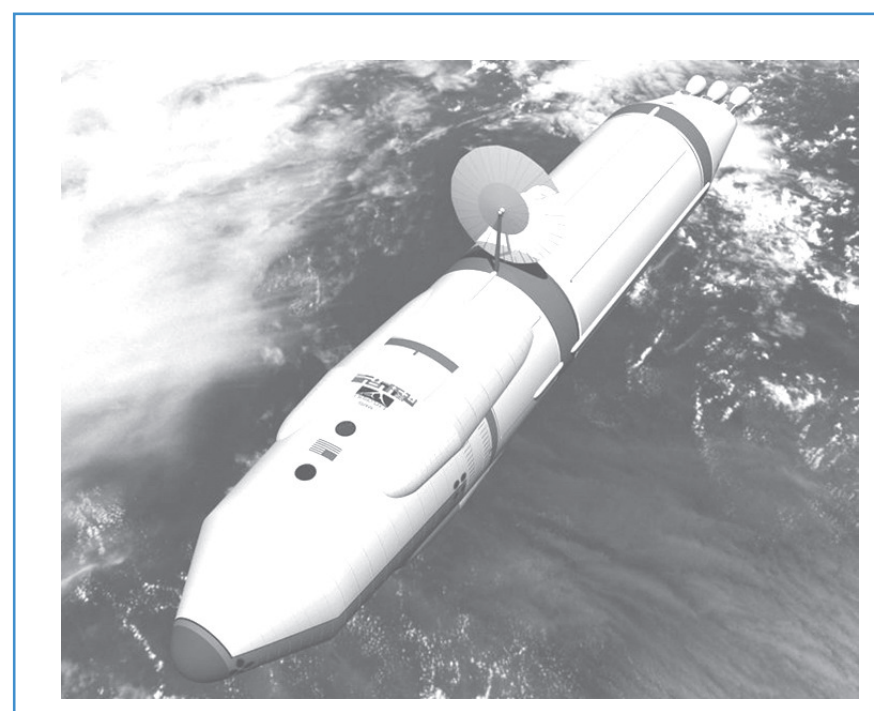

Figure 3: Image from NASA Mission to Mars (www.nasa.gov)
The project selected was open-ended in order to require the teams to define the problem and set limits on the depth of their investigation. The topic was chosen as something the students would be familiar with, to give this large team (8) of strangers a starting point from which to work. There was a mixed response to the topic of the project, with recent outreach project work highlighting that by AS-level students are somewhat over-familiar with Climate Change. Perhaps due to this over-familiarity some teams chose to take a very surface approach, wasting precious report space discussing politics. Some of the students in these groups listed their reason for not liking the topic of the project as it 'doesn't involve physics.' This was unfortunate and was probably, in part, due to insufficient interaction between staff and certain teams. However $77 \%$ of students responded that they enjoyed the experience and found it beneficial, with a further $11 \%$ partially agreeing.

\section{0}

Therefore it was decided that the idea of an introductory project is sound, but the topic should be improved. Further, in order to combat students going off-topic and discussing the politics/financial aspect, the project was designed to consist of a number of steps, which cannot be accessed until the previous one is completed. Two students were hired to spend 3 weeks over the summer gathering together and developing suitable research materials for the chosen topic Mission to Mars. At this stage the project was divided into five interrelated sub-topics:

- Mission Length and Trajectory,

- Mass Management and Launch,

- Communications and Life Support,

- Radiation and Heat Shielding,

- Landing Craft and Re-entry.

With 120 students working on the project for a week, it was decided to divide them in three groups of 40 both to make it easier to obtain suitable levels of students-staff interaction and to introduce an element of competition with all three groups working on the same project in separate rooms. Within in each

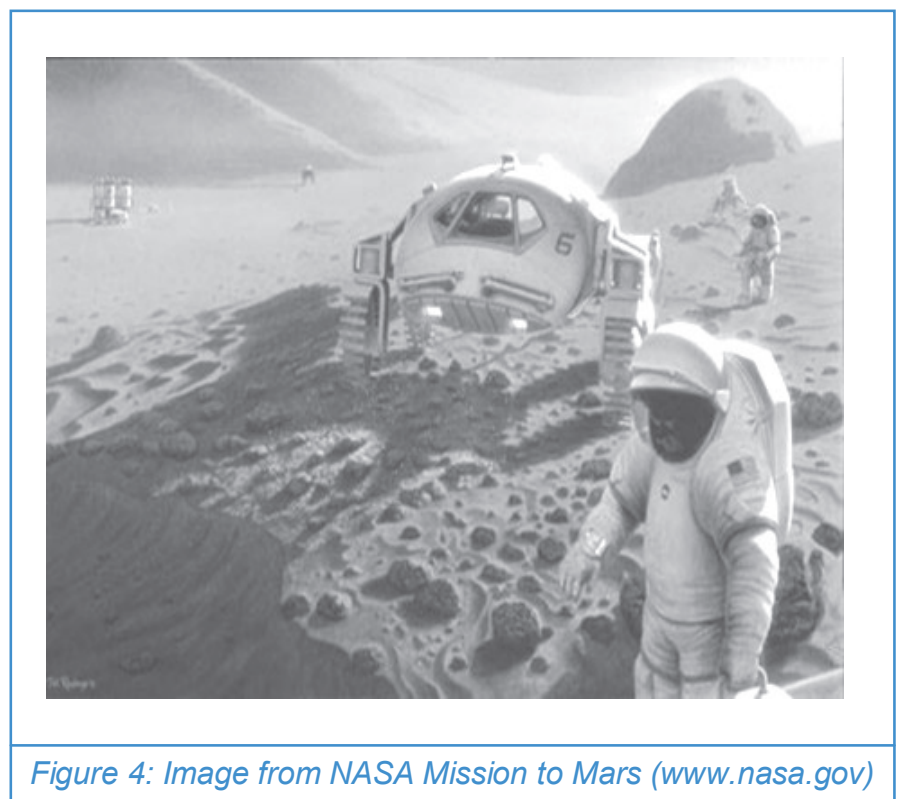


group, the students were further subdivided into 5 teams of 8 . In order to introduce the idea of working toward short-term deadlines as part of the longer-term goal, teams were not assigned a sub-topic. Instead each team was given the five possible sub-topics, outlining how, if selected, they would proceed with their research. The proposals were submitted at the end of the day 1 and judged by a panel. Similarly at the end of each session teams were required to submit a 1-page progress report, with an update of their progress and plans.

Each morning and afternoon session started with a flight director meeting in each room to discuss these progress reports, during which, on day 2 , teams were informed of their success in winning the right to work on that aspect in their group. Research materials consisted of the NASA Mission to Mars document (figures 3,4) and selected research papers in the room, as well selected websites collected together on a Departmental website for the project. This was to reinforce the importance of using peer-reviewed sources, (not Wikipedia or whatever comes up first in the Google search), which had been emphasised in the introduction section on the first morning.

On the final morning, by which stage the research was expected to be complete, final year students (who had completed an optional module on the topic) delivered a session on communicating science in order to help a group of 40 students develop a coherent presentation for that afternoon. The final presentation took place in a lecture theatre in front of all staff associated with year 1 . The groups used prepared materials on flip chart paper, spoke for the set 20 minutes, and to responded well to questions. The winning team were selected by the staff and each given a t-shirt designed for the project (figure 5). All students were also given a mini Mars Bar, which added to the convivial atmosphere as they left on the Friday afternoon.

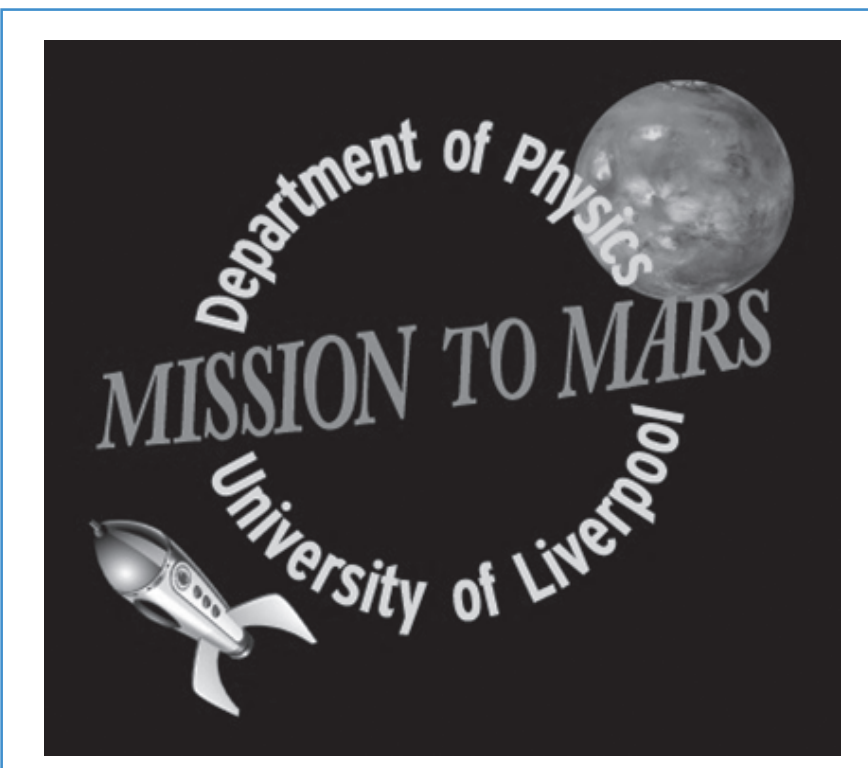

Figure 5: Design on the $t$-shirt given to participants

\section{Mastering Physics}

As the Pearson online assessment tool Mastering Physics has being introduced throughout the year 1 programme, a session was incorporated to allow the students to register with staff support. Feedback from the pilot phase indicated that students did not automatically complete the introductory assessment available, and then had problems with early credit-bearing assessments with basic actions like submitting their answers in the appropriate format. Therefore students were required to complete a short, relevant, introductory assessment, which they found straight-forward but later beneficial according to feedback. They were also given three Mastering Physics homework assignments (Monday due Wednesday, Wednesday due Friday, and Friday due Monday). The dual aims were to enable them to revise some basic, relevant mathematical and physical concepts (e.g. simple dimensional analysis), and to impress upon them the idea that after working $9 a m-5 p m$, they are also required to study/complete work in the evenings.

\section{Evaluation}

Seventy-four students completed a bespoke questionnaire. Although only $54 \%$ indicated the team topic they worked on was their first choice, $94.5 \%$ reported that they were happy with the work done by their team, taking satisfaction in what was achieved, particularly the self-directed learning and freedom to explore potential solutions and manage resources as a group. Comments also mention good communication, working well together and developing skills:

"through lots of extensive research i feel we dismissed lots of unvaluable information and were left with good info" "Learnt a lot and achieved a lot"

When asked if Mission to Mars had helped them settle into university life, $89 \%$ of students responded positively, with the negative $(8 \%)$ comments centring around feeling overwhelmed and lack of guidance at the start, which is not unusual as this is likely their first encounter with PBL:

"developed an idea of how to approach research"

"Increased independence"

"Too much to deal with in first week on top of sorting out bank accounts etc."

More than $50 \%$ of students responded positively (>80\% if include 'somewhat') to feeling they know their way around the Department, know some academic staff, and have command of the basic logistical aspects of being a student at Liverpool. The Mastering Physics introduction and homeworks were felt to be useful by $>75 \%$ of students, with the level about right. Students were asked if they had previous experience of working a team, $60 \%$ said yes, only $4 \%$ said no.

In order to put their responses into perspective, students were also asked if they were surprised by the level of work expected of them. Only 35\% were not surprised, indicating that they had expected a lot of work, with $62 \%$ surprised by either level or quantity, or in some cases both! Overall $54 \%$ of students enjoyed the Mission to Mars project a lot, $27 \%$ a little, with only $7 \%$ indicating that they did not enjoy it at all. All five of these had also indicated that they were surprised by the long hours. In total $34 \%$ (25 students) commented on the length of the day in the open responses:

"9-5 in Uni with mastering physics is harsh" 


\section{Conclusions}

Although it came as a shock to some students, the level and quantity of work expected of them at university was made clear to them in the project. Another aim was to give students experience of working in a team, though $60 \%$ of them claim to have 'a lot' of prior experience of teamwork. It was clear in the project and in semester 1 modules where team work is assessed, that most, including many with prior experience, had yet to develop skills appropriate to working in a team, and benefitted from the early experience of team work.

In the development of the week-long project structure, the emphasis in the introduction was placed on the importance of source material and research skills. In doing so, no time was given to developing the students' skills at working together on an open-ended problem, as was done in the previous year. A short time after the current introduction, devoted to the students solving some short open-ended problems as a team, giving them some early success may contribute to giving them the confidence and skills to set the scope of the larger Mission to Mars.

\section{Secondary to the social aspect students also enjoyed the subject and the work they were doing. Unsurprisingly the international students found it particularly beneficial.}

Students appear to have settled into university life quickly, without the option of 'I didn't know how to print my assignment out' available to them. Mastering Physics registration was smoother than the previous year, and no complaints of insufficient preparation were made when credit-bearing assessments were due.

Students claimed to have found the interaction both with staff and other students beneficial. A direct comparison with previous years is difficult due to changes; the Departmental Student Administrator has been moved to a School role, now with less contact with students, while a central booking system has been introduced which did not locate much of the year 1 timetable in or near the Physics Department. Under the circumstances it is easy to imagine the students having little or no identity as a group, however, they have set up their own study groups for the major modules, making good use of the student notice board in the Department, something recommended but not done in previous years. Further in continuously assessed modules in semester 1 , the percentage of students not completing work (1-2\%) was significantly lower than in previous years $(\sim 10 \%)$.
Overall the students enjoyed the experience and can see the benefit of it being run in the future. Secondary to the social aspect students also enjoyed the subject and the work they were doing. Unsurprisingly the international students found it particularly beneficial.

\section{Future Developments}

There is debate as to whether to make this a credit-bearing module, in which it would lose some of its flexibility from which it gains much of its strength. However it may encourage the participation of those students with an aversion to working in groups or fear of the unstructured nature of open-ended problems. It is intended that the students will not have any lectures/interruptions from other departments allowing them to concentrate and perhaps not feel as 'overwhelmed' by new material competing for their attention. The New Physics integrated approach for year 1 to be introduced in 2011/12 will rely heavily on students working in teams in problem class sessions, which will make the Year 1 Project: Mission to Mars even more relevant than it was this year.

The news has provided some topical issues as possible future topics such as How to cool a nuclear reactor? or How to cap an oil well at the bottom of the ocean?

\section{References}

1. Moran L., (2007), First years enjoying physics? (The Undergraduate Physics Olympics), New Directions in the Teaching of the Physical Sciences, Issue 3. $<$ www.heacademy.ac.uk/physsci/publications/ newdirections>

2. Raine D. and Symons S., (Eds.), (2005), PossiBiLities: A Practice Guide to Problem-based Learning in Physics and Astronomy, The Higher Education Academy Physical Sciences Centre, ISBN 1-903815-14-2.

$<$ www.physsci.heacademy.ac.uk/Publications/ PracticeGuides.aspx> 